\title{
Gravuras nas obras de John Wesley: ilustrações, ornamentos, print flowers e emblemas*
}

\author{
Helmut Renders ${ }^{* *}$
}

\section{Resumo}

A cultura visual wesleyana nasce junto ao aparecimento do metodismo na Inglaterra do século XVIII. Este artigo introduz o uso e o significado variados de gravuras nas obras de Wesley, tanto em livros como em tratados. Conclui-se, primeiro, que as gravuras podem ser classificadas em três grupos distintos: print flowers (emblemas pessoais de impressores e/ou oficinas), emblemas religiosos (gravuras que junto a um título e/ou um texto explicativo criam um tecido novo de ressignificações mútuas) e arte religiosa (gravuras mais complexas de cenas bíblicas). Segundo se percebe, John Wesley incluiu gravuras, com a exceção de retratos, somente em alguns dos seus livros, porém, com tiragens altas e, terceiro, que ele criou o gênero de "emblemas populares", ancorando a sua interpretação em narrativas bíblicas em vez de narrativas das mitologias greco-romanas.

Palavras-chave: Cultura visual religiosa. Cultura visual wesleyana. Gravuras religiosas. Emblemas religiosos. Print flowers.

\section{Engravings in John Wesley's works: illustrations, ornaments, print flowers and emblems}

\section{Abstract}

Wesleyan visual culture is born alongside the appearance of Methodism in England in the 18th century. This article introduces the varied use and significance of engravings

* Agradecemos os/as bibliotecários/as das coletâneas especiais da Biblioteca John Ryland University of Manchester, Inglaterra, em especial Jane Gallagher (Rare Books and Digital Humanities) e Dr. Gareth Lloyd, pela dedicação em atender aos meus numerosos pedidos e pelas muitas sugestões. O time autorizou o registro fotográfico das fontes e a sua eventual reprodução em revistas científicas. Também agradecemos ao Prof. Dr. David Bundy Associate Diretor do Manchester Wesley Research Centre, no Nazarene Theological College, Manchester, pela ajuda logística, hospitalidade, pelo acesso à literatura de vertentes metodistas minoritárias do século XIX e pelas conversas explorando a cultura visual metodista.

** Professor associado II da Universidade Metodista de São Paulo. É pesquisador FAPESP e CNPq e atua em cursos de graduação (teologia) e pós-graduação (Ciências da religião). Contato: helmut.renders@metodista.br. 
in Wesley's works, both in books and treatises. It should first be concluded that the engravings can be classified into three distinct groups: print flowers, religious emblems (engravings that together with a title and/or explanatory text create a new fabric of mutual res-significations) and religious art (more complex engravings of biblical scenes). John Wesley is said to have included engravings, with the exception of portraits, only in some of his books, however, with high print runs, and that he has created the genre of "popular emblems" based on his interpretation of biblical narratives rather than narratives of Greco-Roman mythology.

Keywords: Religious visual culture. Wesleyan visual culture. Religious engraving. Religious emblems. Print flowers.

\section{Grabados en las obras de John Wesley: ilustraciones, ornamentos, print flowers y emblemas}

\section{Resumen}

La cultura visual wesleyana nace junto a la aparición del metodismo en la Inglaterra del siglo 18. Este artículo introduce al uso y al significado variados de grabados en las obras de Wesley, tanto en libros como en tratados. Se concluye, en primer lugar, que los grabados pueden clasificarse en tres grupos dis tintos: print flowers (emblemas personales de impresores y/o talleres), emblemas religiosos (grabados que junto a un título y/o un texto explicativo crean un tejido nuevo de res-significaciones mutuas) y arte religioso (grabados más complejos de escenas bíblicas). En segundo lugar, se percibe que John Wesley incluyó grabados, con la excepción de retratos, sólo en algunos de sus libros, sin embargo, con tiradas altas y, tercero, que él creó, como mínimo en dos casos, "emblemas populares" basando su interpretación en narrativas bíblicas en vez de narrativas de las mitologías grecorromana.

Palabras clave: Cultura visual religiosa. Cultura visual wesleyana. Grabados religiosos. Emblemas religiosos. Print flowers.

\section{Introdução}

Este artigo faz parte de um projeto de pesquisa dedicado ao surgimento da cultura visual evangélica no Brasil. Nesse caso, focamos a cultura visual do protestantismo no seu lugar de origem, no caso, a cultura visual wesleyana. ${ }^{1}$ Para isso, a pesquisa se concentra em gravuras encontradas nas obras escritas e publicadas pelo sacerdote anglicano John Wesley (1703-1791), spiritus rector do movimento metodista na Inglaterra no século XVIII. A relevância dessas obras se explica por razões quantitativas e qualitativas: primeiro, as obras circularam em tiragens significativas e em diversas edições; segundo, trata-se de textos considerados chave pelo próprio movimento. Além disso, adquire esse material um significado adicional pelo fato que as amplas atividades

O projeto conta com o financiamento da FAPESP para um projeto regular. 
publicitárias de John Wesley se direcionaram, com frequência, às classes sociais mais humildes do país, estabelecendo, assim, também uma relação com a cultura popular desse país.

As gravuras em seguida apresentadas, entretanto, não são de uma só natureza ou função. No primeiro capítulo, Gravuras de cenas bíblicas..., identificamos gravuras de cenas bíblicas encontradas em livros. Trata-se de narrativas visuais mais complexas, normalmente com o destaque num motivo central. No segundo capítulo, Gravuras de ornamentação..., avaliamos a importância de fleurons, iniciais, factotums, frontpieces, headpieces, tailpieces e printflowers $^{2}$ em sua qualidade como linguagem da religião. Aqui se misturam o querer do editor ou autor com o fazer dos impressores. No terceiro capítulo, Emblemas populares..., identificamos casos do uso de gravuras como emblemas no sentido clássico renascentista de estabelecer um diálogo entre inscriptio [lema], pictura ou symbolum [imagem] e subscriptio [poesia ou prosa]. Para nós, a última expressão representa a forma mais original da linguagem visual religiosa empregada por John Wesley, a criação de um gênero próprio que nós propomos designar como emblemática social [metodista]. ${ }^{3}$

\section{Gravuras de cenas bíblicas: ocorrências, formas e significados}

Gravuras de cenas bíblicas como ilustrações são raras nas obras de John Wesley e se encontram somente em dois livros editados por ele. ${ }^{4}$ Eles pertencem à sua primeira fase de publicações. Em seguida, apresentamos as respectivas cinco gravuras até agora por nós identificadas. Todas as gravuras de cenas bíblicas pertencem às duas edições do livro Imitatio Christi, de Thomas a Kempis, editado - e abreviado - por John Wesley. John Wesley publicou a obra dessa forma desde 1735, ou seja, antes de viajar para a colônia inglesa de Geórgia, onde ele ficou entre 1736 e início de 1738.

2 Florões, iniciais, factotums, gravuras da capa, gravuras do início da página, gravuras finais, gravuras dos impressores.

3 Originalmente, tínhamos planejados acrescer ainda um quarto capítulo, Retratos de John Wesley e de pregadores, mas, por razões de espaço e suas funções bem específicas muito parecidas, desistimos desse elemento.

4 John Wesley era um intenso e perseverante editor e escritor. Para ter uma ideia tanto da quantidade como da qualidade das suas publicações que contêm centenas de exemplares, conferir a Methodist Collections nas Special Collections da John Ryland Library, University of Manchester [http://www.library.manchester.ac.uk/search-resources/special-collections/ guide-to-special-collections/methodist/] e o Guide to the Wesley Works archive, 1676-1996 and undated, bulk 1724-1791, 1960-1996 na Rubenstein Library da Duke University [https:// library.duke.edu/rubenstein/findingaids/wesleyworks/]. 
Na edição de 1736, quatro gravuras acompanham as páginas iniciais dos primeiros quatro capítulos do livro. Seus títulos - ou incriptios ${ }^{5}$ - são: "Uma só é necessária - Lucas 10,42" (Figura 1), "Vinde a mim, todos os que estais cansados e sobrecarregados, e eu vos aliviarei - Mateus 11.28"7 (Figura 2), "Amarás o Senhor, teu Deus, de todo o teu coração, de todo o teu entendimento de toda a tua alma, de todas as tuas forças - Lucas 10. 27"8 (Figura 3), "Fazei isto em memória de mim - Lucas 22.19" (Figura 4). Os quatro motivos destacam o aspecto afetivo da relação entre o ser humano e Jesus de Nazaré (Figura 1), entre Jesus de Nazaré e o povo humilde (Figura 2), o povo e Deus (Figura 3) e o povo e Jesus Cristo, o ressurreto (Figura 4). Na primeira gravura (Figura 1), Maria expressa afeto pela mão acima do seu coração. Interessantemente, o artista cria uma cena de uma casa bastante culta, com duas figuras na parede. Ambas são femininas e a figura direita parece carregar uma miniatura das duas tábuas dos dez mandamentos e apontar para elas com a mão direita. Talvez devemos imaginar aqui um tipo de representação figurativa de virtude. O Cristo da segunda gravura é mais imponente e autoritativo. Em pé, aponta a sua mão direita para os céus. As figuras masculinas ao seu lado esquerdo e direito parecem mais discutir a sua fala do que acolhê-la e a pessoa na sua frente também parece mais um observador do que um seguidor. A cena é completada por uma mulher com uma criança pequena que está na sombra e que forma um forte contraste com os homens retos e iluminados. Entretanto, considerando o convite expressado pelo subtítulo da gravura, talvez ela seja a mais próxima a Cristo e certamente o alvo do seu afeto.

\footnotetext{
5 Não nos parece impossível identificar nessas gravuras de cenas bíblicas elementos que as aproximem aos emblemas renascentistas. Nós optamos escolher a categoria das ilustrações porque os capítulos são complexos demais para serem reduzidos a um subcriptio de uma só imagem. Como as ilustrações sempre se encontram ao lado esquerdo da primeira página dos primeiros quatro capítulos, se aplicaria também a ideia de um frontpiece por capítulo.

6 "One Thing is needful", Luke 10, v. 42.

7 "Come on to me all that your are Travel and are heavy laden and I will refresh you, Mth 11 V. 28."

8 "Thou shalt love y thy God with all thy heart \& with all thy mind \& with all thy soul \& with all thy strength, Luke $10 \mathrm{~V} .27 . "$

9 "This do in Remberance of Me. Luke 22 V. 19."
} 
Figura 1: Thomas a Kempis, Christian
patterns, 1736 , p. 15 [detalhe: gravura $1^{\circ}$. capítulo].

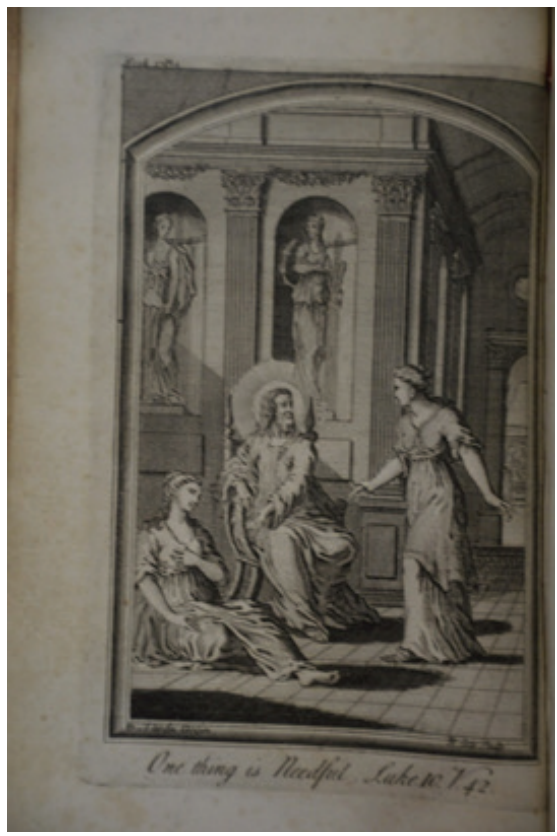

Fonte: Universidade de Manchester, Inglaterra. Biblioteca John Ryland, Coletâneas especiais.
Figura 2: Thomas a Kempis, Christian patterns, 1736 , p. 61 [detalhe: gravura $2^{\circ}$. capítulo].

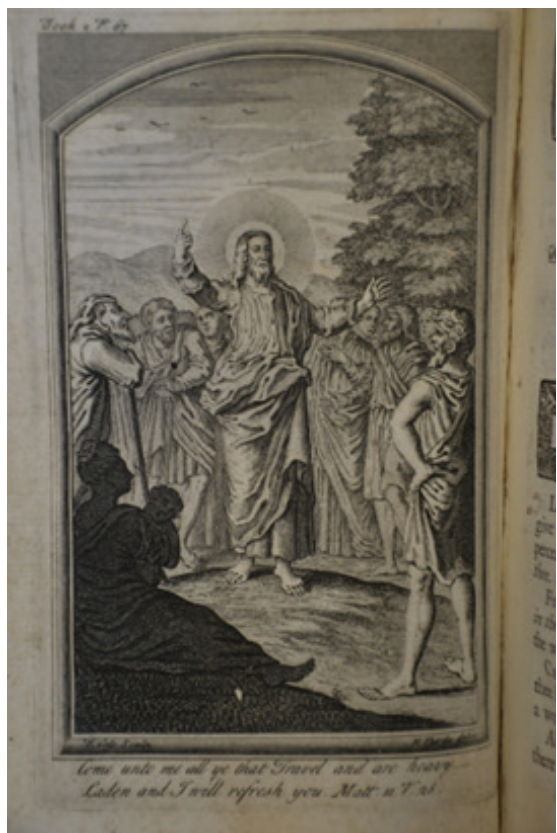

Fonte: Universidade de Manchester, Inglaterra. Biblioteca John Ryland, Coletâneas especiais.

A terceira cena (Figura 3) localiza um jovem Jesus num espaço público. Ele é cercado por homens mais velhos, alguns com vestimentas que lembram sacerdotes, outros parecem mais filósofos. O público parece discutir a sua mensagem, sem demonstrar muita concordância. A quarta gravura (Figura 4) representa a Santa Ceia no momento que Jesus levanta o cálice e diz "Isso é meu sangue..." Ao redor dele se encontram sentados onze discípulos, enquanto um décimo segundo, já de costas ao grupo e a Jesus, está saindo. Toda cena é caracterizada por uma forte tensão entre a luz ao lado esquerdo e a escuridão ao lado direito. Atrás de um muro que divide a gravura pela metade aparece uma cabeça que assemelha um sacerdote. As quatro gravuras foram esculpidas por Benjamin Cole (1695-1766), ${ }^{10}$ um gravurista, cartógrafo e fabricante de instrumentos musicais, óticas e matemáticas que viveu em Oxford, Inglaterra.

10 Cf. "B. Cole sculp" no canteiro esquerdo inferior da moldura da gravura. 
Figura 3: Thomas a Kempis, Christian patterns, Figura 4: Thomas a Kempis, Christian 1736, p. 106 [detalhe: gravura $3^{\circ}$. capítulo]. patterns, 1736, p. 106 [detalhe: gravura $4^{\circ}$. capítulo].

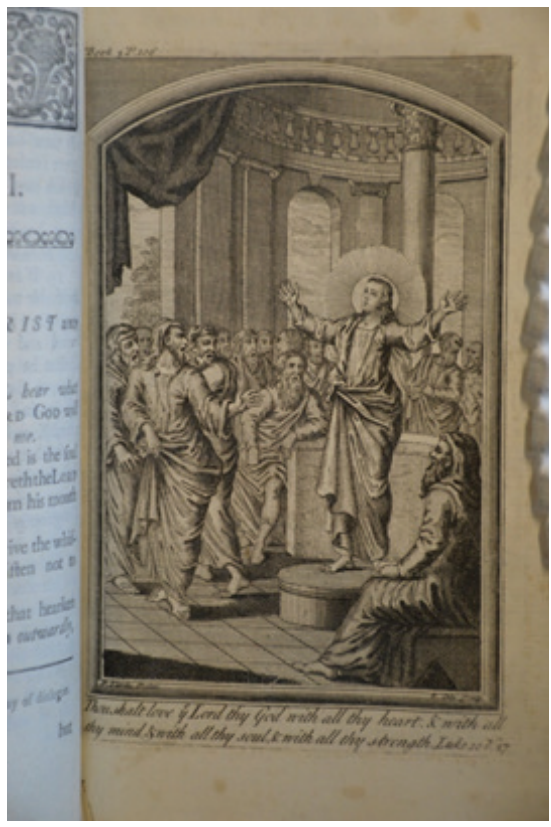

Fonte: Universidade de Manchester, Inglaterra. Biblioteca John Ryland, Coletâneas especiais.

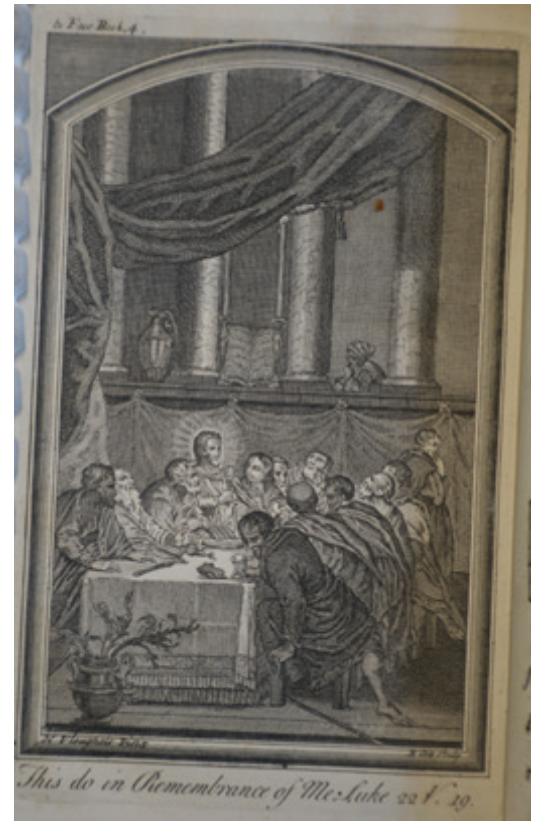

Fonte: Universidade de Manchester, Inglaterra. Biblioteca John Ryland, Coletâneas especiais.

Vistas em conjunto, o tom temático nessas quatro gravuras está numa proximidade sem medo e num compromisso mútuo (Figura 2 e Figura 3). Esse tema também aparece na primeira gravura, expressa pela combinação "coração = afeito" + "mandamentos = responsabilidade ou santidade". ${ }^{11}$ Dessa forma, antecipam as quatro gravuras de 1738 dois grandes temas do movimento metodista. A quinta gravura é de outra edição de John Wesley da Imitatio Christi do ano 1735, publicado em um formato bem menor (Figuras 3 e 4) do que a primeira. Existiam edições com a imagem de um crucifixo reproduzido em seguida.

Considerando que essa versão de tamanho menor viu, até o ano 1791, 45 edições na Inglaterra, 35 edições na América do Norte e 1 edição no País

\footnotetext{
11 Afeto e compromisso mútuo parecem antecipar a clássica ênfase wesleyana em "graça e responsabilidade".
} 
de Gales, deve-se rever um pouco a questão da relativa ausência de gravuras com cenas bíblicas na ampla obra de John Wesley. ${ }^{12}$ As edições de Wesley da obra de Tomas a Kempis não passaram simplesmente por tiragens altas, mas as tiragens altas serviram um propósito de empoderamento das classes mais humildes: Os Christian Pattern - o padrão cristão - era considerado ao lado do livreto Primitive Physic - Medicina popular (cf. RENDERS, 2011, p. 339-353) - o vade-mécum duplo de qualquer casa metodista.

Figura 5: Thomas a Kempis, Christian Figura 6: Thomas a Kempis, Christian patterns,

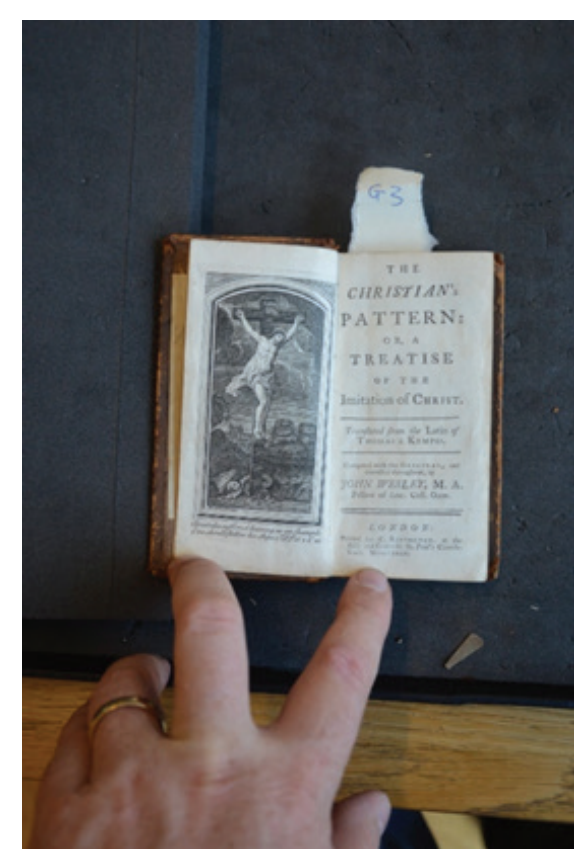
patterns,

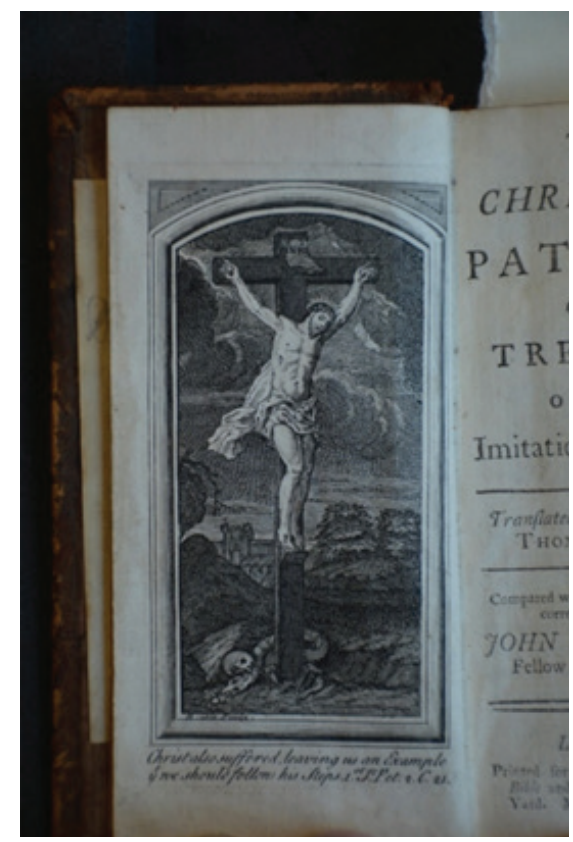

Fonte: Universidade de Manchester, Fonte: Universidade de Manchester, Inglaterra. Biblioteca John Ryland, Coletâneas Inglaterra. Biblioteca John Ryland, Coletâneas especiais. especiais.

12 Ian Green (2000, p. v-xiii) argumenta em sua introdução que textos intermediários entre escritos acadêmicos e tratados populares deveriam ser mais considerados para compreender o mundo protestante inglês dos séculos XVII e XVIII. Como demonstra esse artigo, John Wesley certamente contribuiu tanto com textos intermediários, menos controversos, como com tratados populares. 
Os dois textos eram um investimento estratégico na agência da população humilde quanto à sua vida religiosa como à sua saúde, quanto ao salus como ao sanus. E justamente nesse pacote as raras gravuras de cenas bíblicas estiveram presentes.

\section{Gravuras de ornamentação: ocorrências, formas e significados das print flowers}

A maioria das gravuras encontradas nas obras de John Wesley era de gravuras de ornamentação. Entre essas gravuras se distinguem, classicamente, os seguintes tipos:

Ornamentação: relevo cortado de madeira ou metal, usado por impressores para fins decorativos ao imprimir textos de tipografia. Ornamentos podem tomar a forma de headpieces (encontrados no início do capítulo ou outras seções de um livro) e fleurons, tailpieces (encontrado no final de capítulo ou outras secções de um livro), iniciais (letras iniciais grandes no início dos parágrafos), ou factotums (peças ornamentais nas quais um espaço é deixado para o tipo de qualquer letra do alfabeto pode ser inserido) (FLEURON, 2018).

Desde cinco tipos, os fleurons, iniciais e factotums, têm, em geral, um significado mais decorativo, especialmente quando se trata de formas não figurativas com motivos de flores (de onde vem a palavra fleuron) ou com letras.

Um factotum, entretanto, também pode conter figuras, símbolos ou emblemas inteiros. Headpieces e tailpieces podem ser fleurons, ou seja, composto basicamente por motivos de flores, mas, eventualmente, eles contêm também elementos figurativos ou simbólicos. Nós acreditamos que seja útil ainda distinguir dos beadpieces os frontpieces, porque uma coisa são as gravuras no início das páginas (beadpieces) e outra as gravuras nas capas. Não era incomum impressores usarem para suas obras frontpieces especiais, que se chamam nesses casos também como printer flowers, ou seja, fleurons de impressores. Como numa só obra frontpieces, headpieces e tailpieces não são iguais, fica evidente que eles não assumem paralelamente o significado único de printer flowers, de definir a descendência da obra para indicar a oficina ou o impressor, eventualmente, até o ano da produção. ${ }^{13}$ Nas obras de John Wesley, todos esses tipos de ornamentação aparecem, mas, combinações completas são raras e mais

13 O artigo de Frank Baker (s.a., p. 2) sobre Printer flowers segue esta direção: "Identificar impressores onde eles são desconhecidos [garantir dados próximos àquelas publicações não datadas". Confira também Hazel Wikinson (2013, p. 70-79). 
reservadas aos livros da primeira fase das suas publicações. O que mais se tem são frontpieces, e uma sistemática comparação do seu uso. Comparando, ano, local e impressor, fica evidente que se trata de fato de printer flowers. Isso pode ser evidenciado na próxima figura (Figura 7) que contém oito capas de diferentes edições do "Sermão sobre a Salvação pela Fé"14 de John Wesley.

Figura 7: John Wesley, "Sermão sobre a Salvação pela fé". Oito capas de diferentes edições.

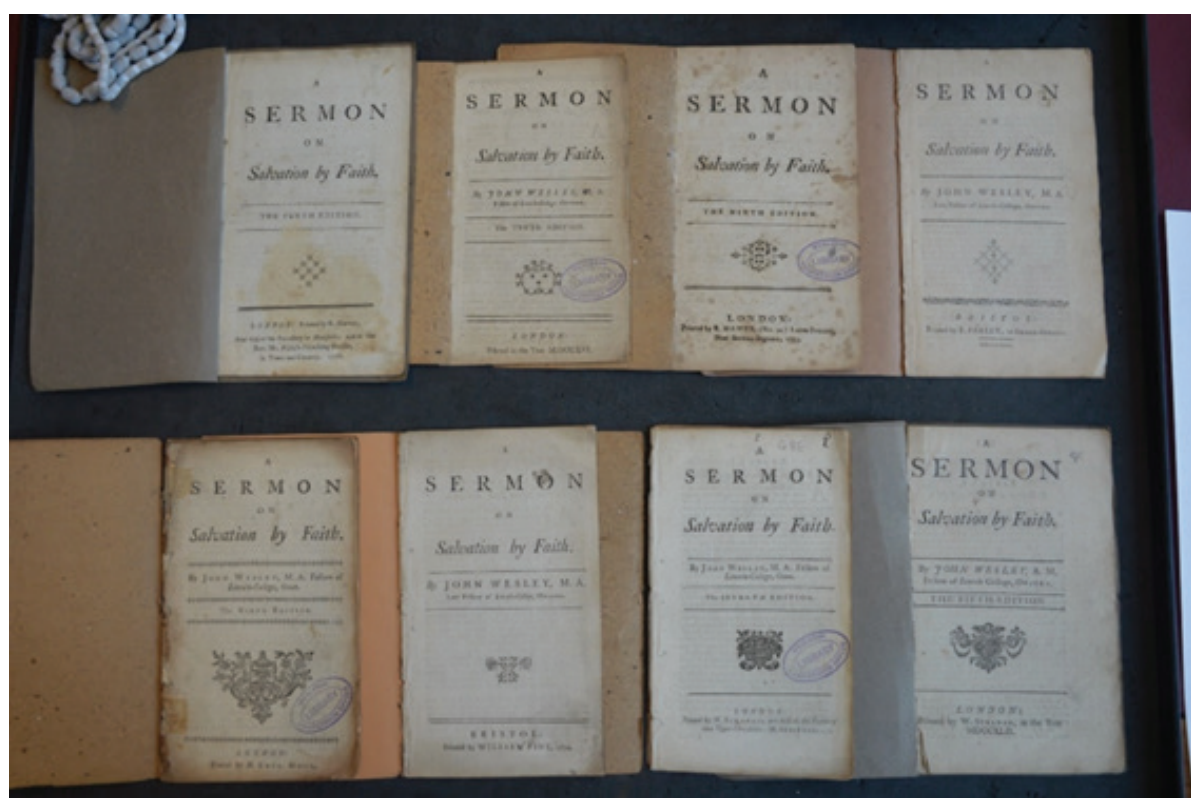

Fonte: Universidade de Manchester, Inglaterra. Biblioteca John Ryland, Coletâneas especiais.

Essas printer flowers se tornaram a partir de 1754 completamente abstratas, ${ }^{15}$ mas, continuavam sendo usadas como indicação ou dos

14 Parte superior, da esquerda para a direita (1) Londres, impressor R. Harwey, 10 a edição, 1778; (2) Londres, $10^{a}$ edição, 1756; (3) Londres, R. Haes, 9a edição, 1773; (4) Bristol, impressor E. Farley, sem edição, 1763. Parte inferior, da esquerda para a direita: (5) Londres, impressor H. Cock, 9a edição, 1750; (6) Bristol, impressor William Pine, sem número de edição, 1770; (7) Londres, impressor não legível, $7^{\text {a }}$ edição, 1745; (8) Londres, impressor W. Strahan, $5^{\text {a }}$ edição, 1742.

15 A primeira capa com uma gravura abstrata era o texto A short view... between the Moravian editado em Bristol 1748. Entretanto, em Bristol voltam depois ainda as printer flowers. Já a partir de 1754, aparecem formas abstratas em Londres, onde depois nunca mais se usava nas frontpieces qualquer tipo de fleuron. 
impressores, ou das suas oficinas, ou os dois. ${ }^{16}$ Com isso as frontpieces, mesmo que contenham até motivos simbólicos e/ou figurativos etc. não servem como indicadores teológicos quanto ao autor, porque não são vinculados com o texto, nem passou a sua escolha pelas mãos de John Wesley. Mostramos em seguida dois exemplos bem distintos: uma printer flower no estilo de um Fleuron (Figura 8) e outra com significados simbólicos (Figura 9) com uma pessoa coroada sentada numa poltrona ou num trono segurando um cetro na mão esquerda e um prato - eventualmente um espelho - na mão direita.

Figura 8: John Wesley. Salvação pela fé, $9^{a}$ edição, Londres: 1750, capa [Ornamento usado pelo impressor H. Cock].

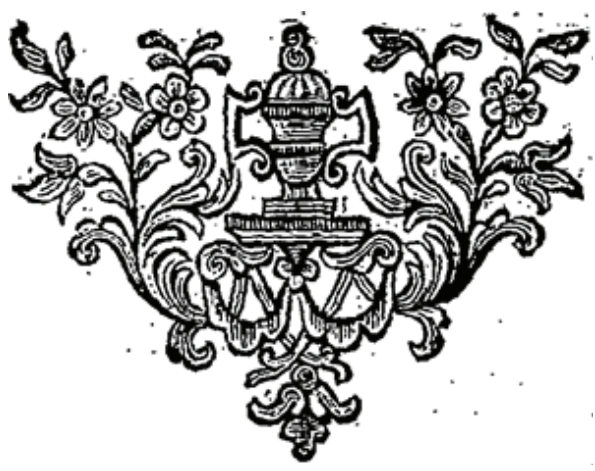

Fonte: Universidade de Manchester, Inglaterra. Biblioteca John Ryland, Coletâneas especiais.
Figura 9: John Wesley. Uma palavra oportuna, ou um conselho para um homem inglês, $8^{\mathrm{a}}$ edição, Londres: 1745, capa [Ornamento usado pelo impressor W. Stratham].

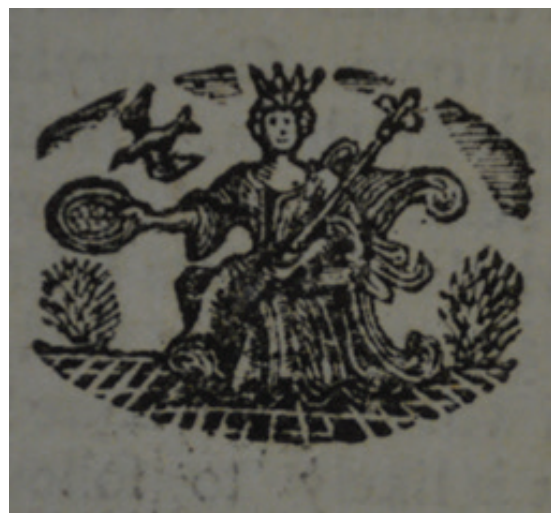

Fonte: Universidade de Manchester, Inglaterra. Biblioteca John Ryland, Coletâneas especiais.

A combinação de coroa, cetro e espelho pertence à representação simbólica da luxúria (Figura 9). A partir de 1754 (cf. Figura 7), as printer "flowers" se tornaram abstratas, sem significados simbólicos.

Como os headpieces e tailpieces não repetem os frontpieces, eles são mais candidatos para uma interpretação simbólica. Veja, por exemplo, um dos

\footnotetext{
16 Fizemos o teste com 120 tratados, publicados entre 1739 e 1790, impressos em Bristol, Dublin, Newcastle upon Thyne ou Londres. Como resultado resumimos: (a) cada printer flower existe somente em uma das quatro cidades; (b) Muitas vezes, há também um uso restrito a um só ano; (c) em seis casos, uma printer flower específica foi usada no mesmo lugar durante dois anos.
} 
headpieces do livro "O caráter de um metodista de 1748” (Figura 10). Além dos motivos florais dominantes, há ainda os motivos figurativos de um livro aberto (centro) e quatro pássaros, abrindo ou fechando as suas asas.

Figura 10: John Wesley, O caráter de um metodista, 1743 [detalhe: gravura na última página].

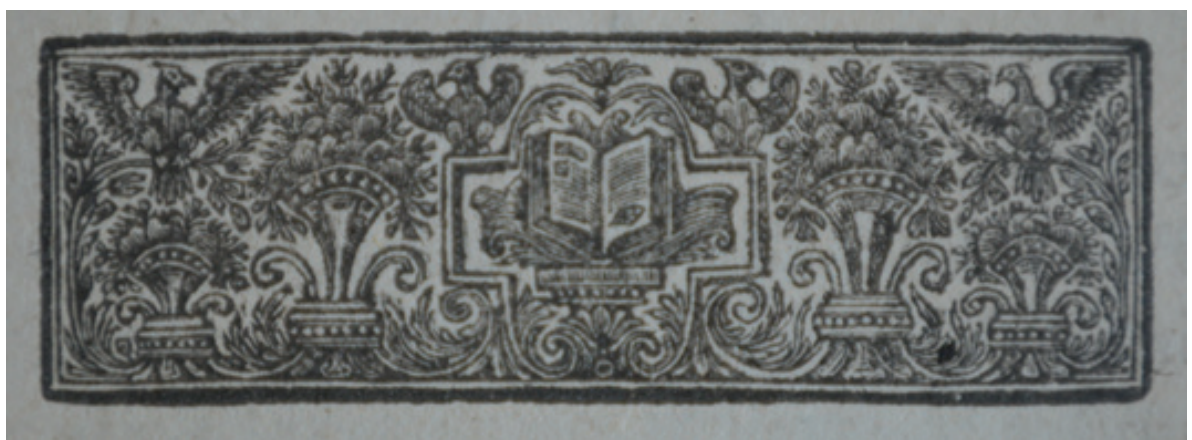

Fonte: Universidade de Manchester, Inglaterra. Biblioteca John Ryland, Coletâneas especiais.

Como o livro aberto mostra, aparentemente tanto linhas de textos como um headpiece, um inicial ou factotum e um tailpiece, trata-se, provavelmente, não do "livro dos livros", ou de uma Bíblia. Já os pássaros podem representar ou uma águia ou uma fênix (símbolo de ressurreição). Especialmente por causa da incerteza em relação à Bíblia, pode se perguntar se se trata de um motivo religioso ou humanista. Isso não é conclusivo.

Figura 11: John Wesley. O caráter de um metodista, 1742

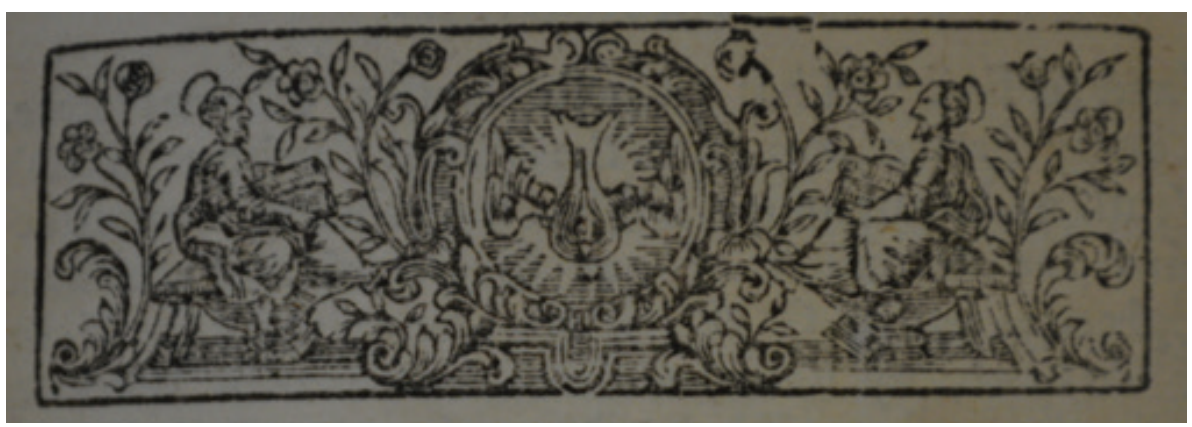

Fonte: Universidade de Manchester, Inglaterra. Biblioteca John Ryland, Coletâneas especiais. 
No beadpiece anterior do livreto O caráter de um metodista (Figura 11) encontram-se no meio de flores nas meio-laterais duas pessoas com auréola ou halo e na parte central dentro de uma moldura redonda uma pomba descendo acima de um círculo de raios claros, indicando que a pomba representa o Espírito Santo. A referência ao Espírito Santo faz todo sentido no início dessa obra. Considerando que a figura esquerda representa um homem mais velho e a figura ao lado direito um homem mais jovem, poderia se tratar de uma representação da trindade.

Figura 12: John Wesley, Regras das Sociedades de Bandas, 1738, p. 1 [Headpiece].

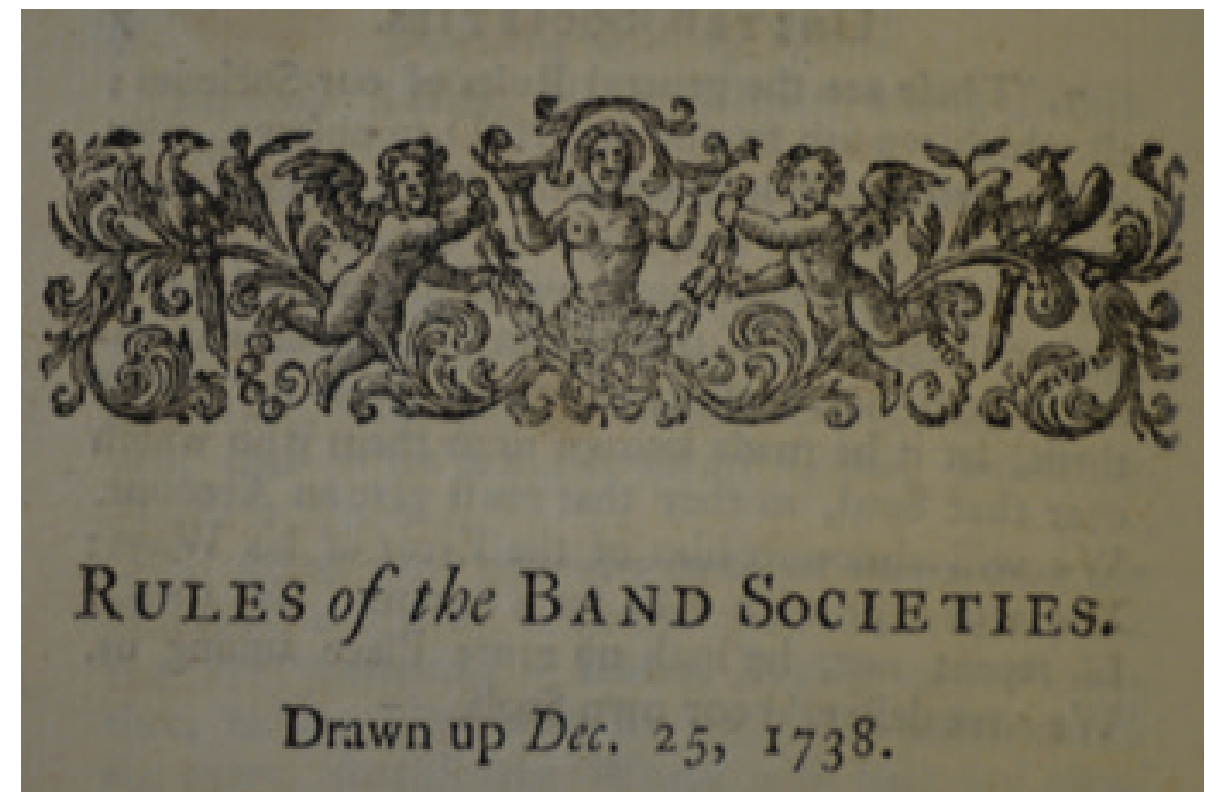

Fonte: Universidade de Manchester, Inglaterra. Biblioteca John Ryland, Coletâneas especiais.

Mais outro exemplo parece mais curioso e menos focado em uma mensagem religiosa. Ele pertence também à fase inicial do movimento metodista e aparece num tratado com o nome Regras das Sociedades de Bandas de 25 de dezembro de 1738 (Figura 12). Sociedades de bandas (band societies) era um de três tipos de pequenos grupos do metodismo inglês (Classes: participação obrigatória de todos os membros; bands: reuniões de pessoas convertidas; band society: pessoas convertidas em busca do aperfeiçoamento da fé). O headpiece desse tratado combina florais, pássaros alegóricos, dois 
anjos (ambos têm, no mínimo, uma asa), e uma figura feminina no centro parecida à parte superior de uma sereia, apesar de os seus cabelos serem muito curtos para isso. Seja como for, um sentido especificamente cristão não se instala pela imagem.

Semelhantes aos casos dos headpieces, nos parecem também os casos dos tailpieces. Nas obras de Wesley, eles são muito menos comuns do que os frontpieces e parecem ter como primeiro propósito a função estética de preencher o espaço deixado vazio na última página do texto. Apesar de que eles não repetem os motivos das gravuras da capa, ou seja, não se trata de printer flowers, eles também não funcionam como emblemas. Mas, eventualmente, eles se comunicam com o texto anterior.

Figura 13: John Wesley, O caráter de um Figura 14: John Wesley, Considerações... Metodista, 1742 [tailpiece]. doutrina da eleição, 1740 , p. 12 [tailpiece].

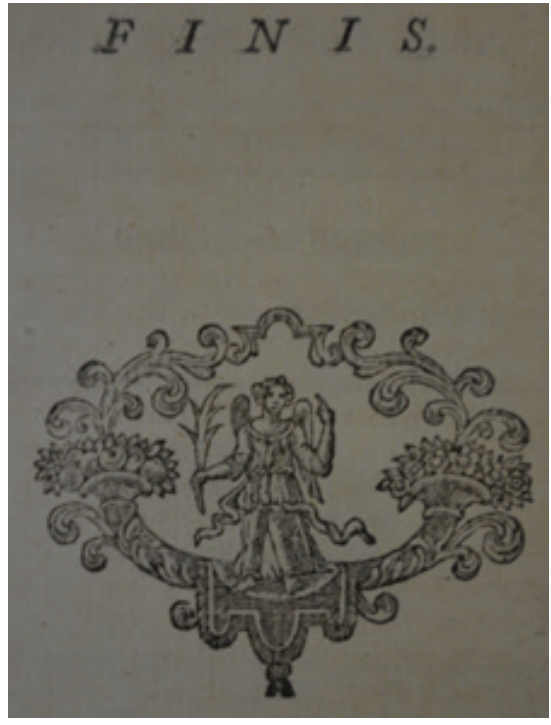

Fonte: Universidade de Manchester, Inglaterra. Biblioteca John Ryland, Coletâneas especiais.

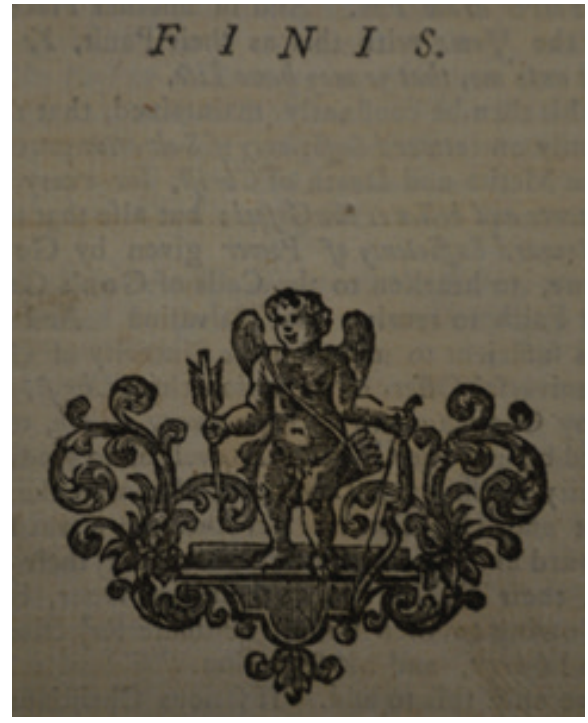

Fonte: Universidade de Manchester, Inglaterra. Biblioteca John Ryland, Coletâneas especiais.

Os dois exemplos demonstram a sua variedade. Novamente, encontramos ao lado de motivos florais representações figurativas (Figuras 13 e 14). A primeira figura (Figura 13) tem duas asas, segura um ramo na sua mão direita e aponta com a sua mão esquerda para as alturas. Segundo a 
iconografia cristã, trata-se de um anjo que indica o caminho aos céus e que eventualmente segura lílias como símbolo da santidade. Nesse caso, no fim do livreto $O$ caráter de um metodista de 1742, um anjo indicando o caminho da santidade como o caminho aos céus, faz sentido. No outro caso (Figura 12), retrata um cupido, prestes a lançar uma flecha. Essa imagem, no final de um tratado sobre a doutrina da eleição, articula a ênfase metodista na eleição pelo amor e para o amor. Nos dois casos, então, as gravuras parecem escolhidas em função do texto.

Outro caso de um tailpiece é, no mínimo, curioso. No exemplo em seguida (Figuras 15 e 16), trata-se de uma das raras referências diretas à mitologia grega.

Figura 15: John Wesley. Um Figura 16: John Wesley. Um breve olhar a respeito das breve olhar a respeito das diferenças entre os irmãos morávios [...] e os irmãos diferenças..., 1745 John e Charles Wesley 1745 [detalhe gravura "Apolo e Dafne"]
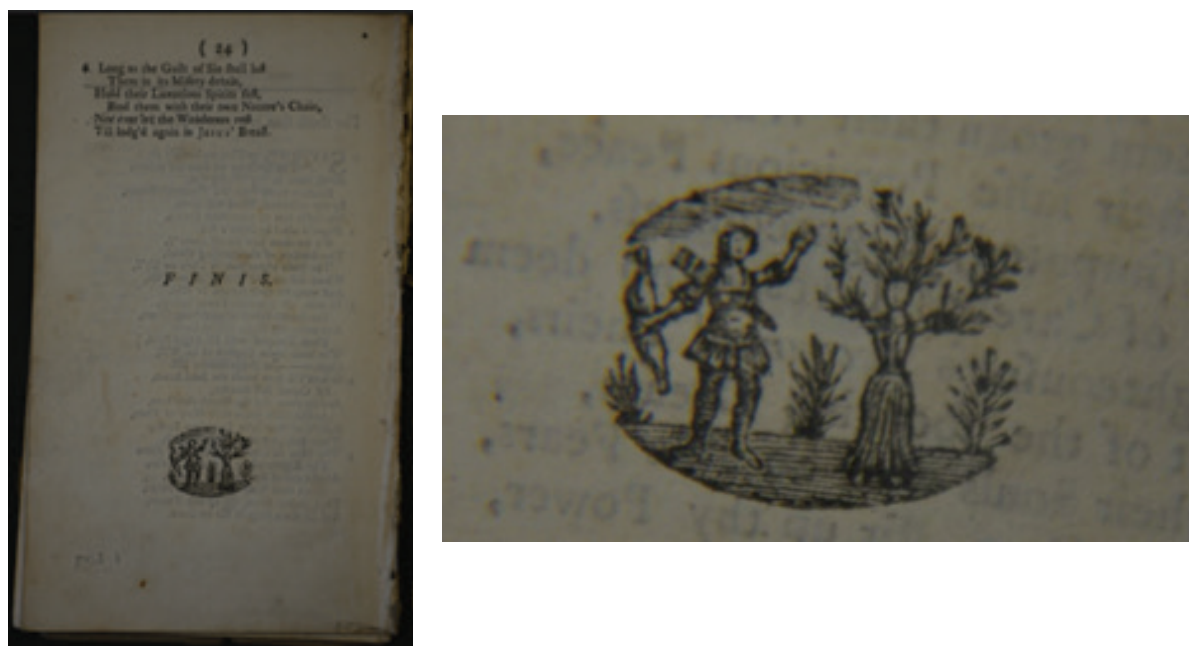

Fonte: Universidade de Manchester, Inglaterra. Biblioteca John Ryland, Coletâneas especiais.

Fonte: Universidade de Manchester, Inglaterra. Biblioteca John Ryland, Coletâneas especiais.

No emblema encontramos, ao lado esquerdo, uma figura masculina com um arco em sua mão direita, flechas atrás das suas costas e sua mão esquerda erguida. Já ao lado direito há uma figura feminina com braços 
erguidos e ramos crescendo das suas mãos e da sua cabeça. Trata-se da lenda de Apolo e Dafne, apesar de que retrata somente o cupido e Dafne. Segundo a lenda, o cupido teria lançado uma flecha de ouro para Apolo que, então, apaixonou-se por Dafne, e uma flecha de chumbo para Dafne, para que ela jamais se apaixone por Apolo. Apolo foi então atrás de Dafne e Dafne fugiu de Apolo para, finalmente, se transformar em uma árvore e dessa forma escapar do desejo de Apolo. Apesar de o significado desse emblema ser claríssimo, seu papel nesse lugar não fica claro. Trata-se de uma escolha do impressor que passou despercebido? Ou há uma ligação entre emblema e texto que trata da relação entre morávios e metodistas? ${ }^{17}$ Provavelmente trata-se do primeiro caso, já que a segunda edição desse tratado publicado em Bristol em de 1748, tem o mesmo emblema como a figura 18 que claramente pertence ao impressor Felix Farley que o ainda usou em 1753. Concluímos essa parte com a distinção entre printer flowers e gravuras ornamentais que não têm uma relação com o texto e beadpieces e tailpieces que eventualmente estabelecem um diálogo com o texto. Como nós não conseguimos relacionar o tailpiece de Apolo e da Dafne com um impressor, fica a questão em aberta.

\section{Emblemas populares: ocorrências, formas e significados de emblemas}

Com o terceiro tipo ou uso de gravuras, o uso como emblema, voltamos, por um lado, para as origens do uso renascentista de gravuras e sua composição cuidadosa de títulos, gravuras e o texto em si, ou de inscriptio, pictura/symbolum e subscriptio. ${ }^{18}$ Mas como Wesley usa emblemas, na sua época ainda bem conhecidas em Oxford ${ }^{19}$ Para quem ele se dirige e o que eles significam?

\footnotetext{
17 Existe na história dos morávios de fato uma situação que desenvolve poligamia e amor livre que envolve o filho de Zinzendorf e a criação de uma aldeia perto da fronteira com a França.

18 O metodismo foi visto pelos seus contemporâneos, no século XVIII, como antimoderno por natureza (ANDERSON, 2011). Nessa perspectiva, trata-se de um sequestro de gênero.

19 Lembramos que não se aprendeu nas universidades "ler" emblemas, mas, também "criar" emblemas.
} 
Figura 17: John Wesley. Uma palavra para uma pessoa... 1753 [detalhe: capa].

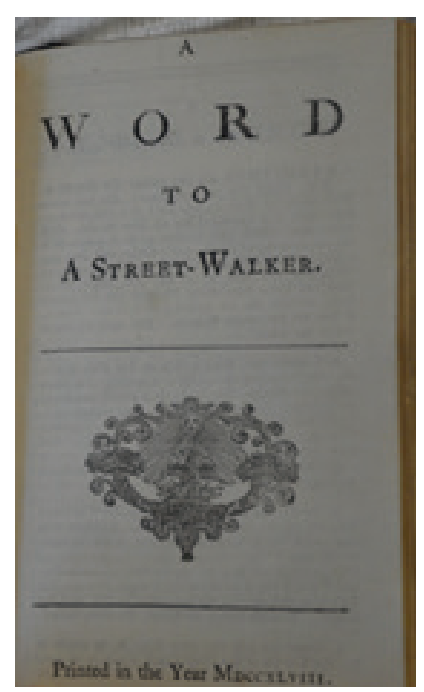

Figura 18: John Wesley. Uma palavra para uma pessoa que anda pela rua, 1753 [detalhe: pictura na capa].

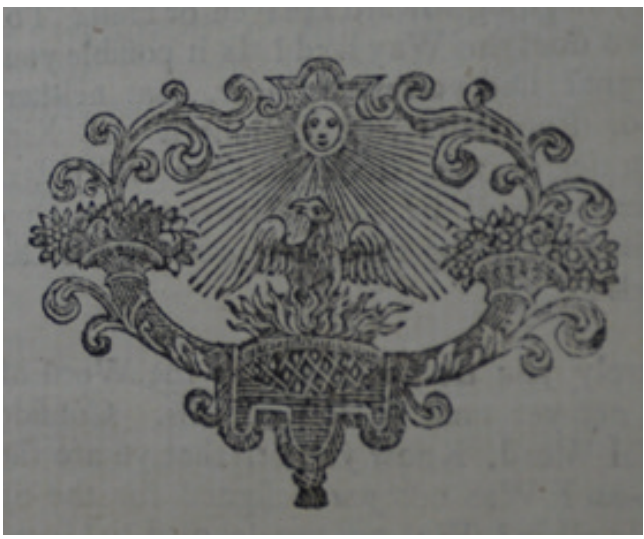

Fonte: Universidade de Manchester, Fonte: Universidade de Manchester, Inglaterra. Inglaterra. Biblioteca John Ryland, Biblioteca John Ryland, Coletâneas especiais. Coletâneas especiais.

O primeiro exemplo (Figuras 17 e 18) é um tratado que se dirige às prostitutas que procuram seus clientes nas ruas (street-walker). Nos parágrafos 1 e 2 Wesley alerta sobre o suposto destino de cada ser humano (Para onde você está indo? Para o céu ou para o inferno?). No parágrafo 3, ele supõe que as endereçadas querem tomar a Bíblia a sério e afirma que cada ser humano pode ser o templo do Espírito Santo (parágrafo 5). Depois de mencionar as consequências físicas (doenças) e o sofrimento causado (entre amigos e as próprias prostitutas) ele parte da alegação "Mas eu não tinha mais amigos" para introduzir Jesus Cristo como amigo em todas as situações. Obviamente, esse texto milita para um recomeço, da condenação para a sinalização de perdão e acolhida. A pictura representa essa dinâmica. O sol que brilha de cima é uma referência a Mateus $5.43-46,{ }^{20}$ que destaca o caráter universal

20 Mateus 5.43-46: "Amai a vossos inimigos, bendizei os que vos maldizem, fazei bem aos que vos odeiam e orai pelos que vos maltratam e vos perseguem, para que sejais filhos do Pai que está nos céus; porque faz que o seu sol se levante sobre maus e bons e a chuva desça sobre justos e injustos. Porque, se amardes os que vos amam, que recompensa tendes? Não fazem os publicanos também o mesmo?” 
da graça de Deus - uma doutrina chave do metodismo - e rejeita atitudes farisaicas. O pássaro que surge das chamas é uma fênix que surge das cinzas, símbolo da ressureição da morte, considerando que os metodistas falavam tanto da transformação da vida antes da morte como da vida depois da morte.

Figura 19: John Wesley. Uma palavra para um bêbado, 1753 [detalhe: capa].

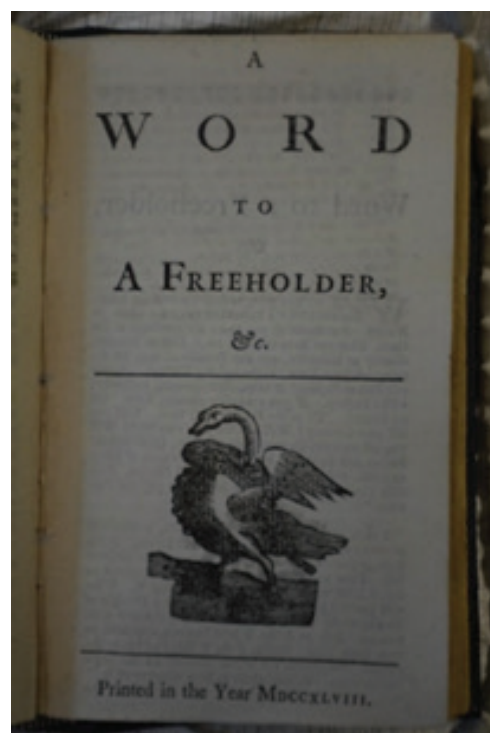

Fonte: Universidade de Manchester, Fonte: Universidade de Manchester, Inglaterra. Biblioteca John Ryland, Coletâneas Inglaterra. Biblioteca John Ryland, Coletâneas especiais.
Figura 20: John Wesley. Uma palavra a uma dona da terra, 1753 [detalhe: capa].

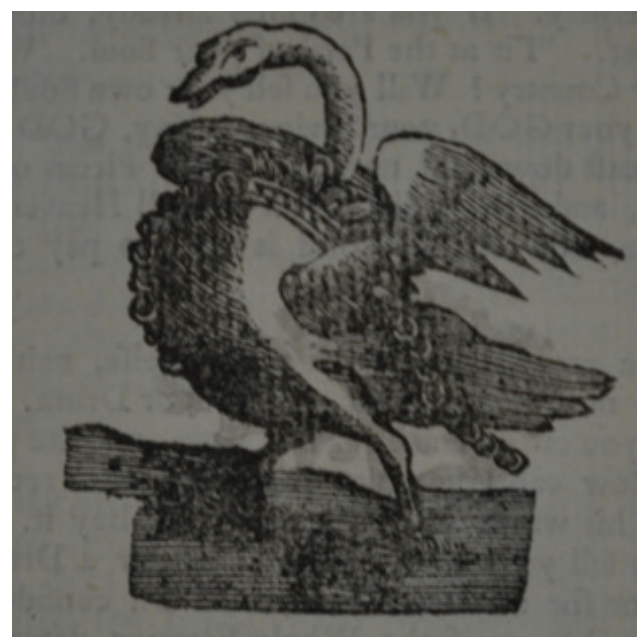
especiais.

O segundo emblema (Figuras 19-20) é algo popular e tipicamente britânico. O cisne é um pássaro que aparece em muitos contos de fadas. Eles representam castidade (plumagem branca) e fidelidade (monogamia, porque eles acasalam com o mesmo parceiro por toda a vida). Na Inglaterra, se manteve a ênfase na lealdade e combinação com a força e a realeza (pássaro simbólico da monarquia inglesa). No caso da pictura do emblema, trata-se do conflito entre o cisne como símbolo de virtude real e a serpente como símbolo do mal. Como essa simbologia se relaciona com o título e o texto do tratado? Um freeholder era uma pessoa com direito à terra sem limites de uso. Ligado com essa condição era o direito de voto aos representantes do parlamento inglês. O texto de John Wesley discute questões de compra 
de voto e da escolha dos candidatos cujos frutos das suas ações deveriam falar a respeito deles e finaliza com a afirmação que eles deveriam amar seu país, amar o rei e amar a igreja. Assim o cisne e a serpente simbolizam tanto o conflito da escola pura ou pervertida do próprio freeholder como seu dever de referenciar a casa real, no caso, o rei George e não ele mesmo se transformando na serpente que "estrangula" o rei. Nesse caso, não domina uma narrativa bíblica a interpretação, mas, uma narrativa nacional.

Figura 21: John Wesley. Uma palavra para um bêbado, 1753 [detalhe: capa].

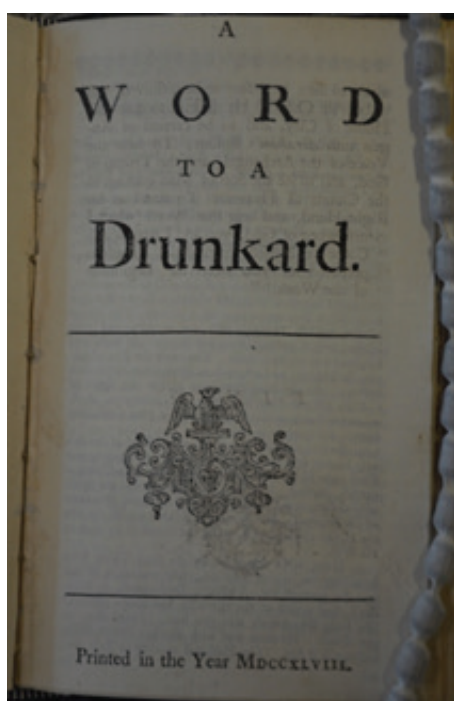

Figura 22: John Wesley. Uma palavra a uma dona da terra, 1753 [detalhe: capa].

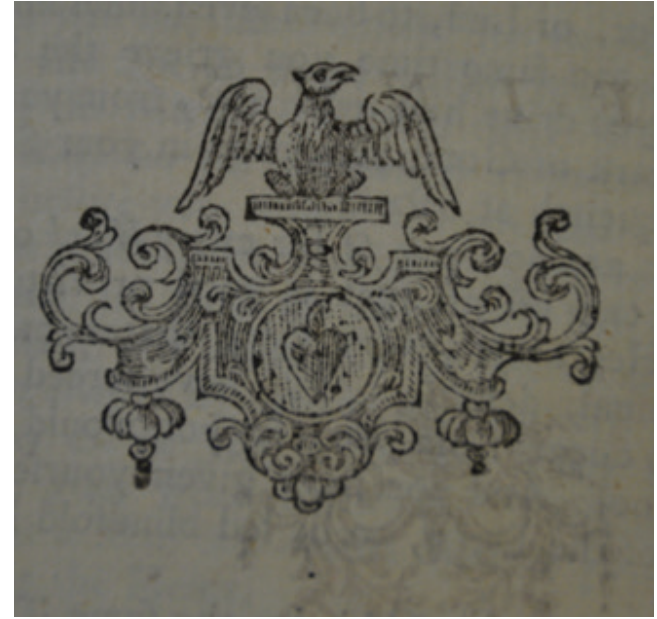

Fonte: Universidade de Manchester, especiais.

Inglaterra. Biblioteca John Ryland, Inglaterra. Biblioteca John Ryland, Coletâneas Coletâneas especiais.

O terceiro emblema (Figuras 21-22) já analisamos em outro lugar (RENDERS, 2014, p. 83-95) e resumimos somente o resultado. A pictura é composta por um coração com chamas como representação da benignidade e misericórdia de Deus e um pássaro prestes a voar que identificamos como águia. Junto às passagens bíblicas de Êxodo $19.4^{21}$ e Isaías $40.31^{22}$ como

21 "Vós tendes visto o que fiz aos egípcios, como vos levei sobre asas de águias, e vos trouxe a mim."

22 "Mas os que esperam no Senhor renovarão as forças, subirão com asas como águias; correrão, e não se cansarão; caminharão, e não se fatigarão." 
chave de interpretação sinaliza-se pela pictura a possibilidade de se levantar novamente, de transformar uma vida em pedaços em uma vida nova, pelo amor e pela graça de Deus. ${ }^{23}$

Nos três casos, podemos, primeiro, excluir a possiblidade de que se trata simplesmente de printer flowers. Como nenhuma das gravuras é encontrada em outra obra de John Wesley, isso nos parece comprovado. Segundo, evidenciamos que as interpretações não requerem conhecimentos específicos da mitologia greco-romano, mas, de narrativas bíblicas e de um dado cultural inglês, algo que se pode supor como do conhecimento do povo. Por causa disso concluímos que se trata de fato de emblemas e, especialmente, no primeiro e terceiro caso, de emblemas direcionados "ad populum", emblemas criados para o povo humilde, em especial, para pessoas em circunstâncias de crise e de alta vulnerabilidade. Wesley transforma, a partir de 1748, um gênero humanista em um gênero popular que em si já transfere uma mensagem de inclusão e de convicção da capacidade do povo ler e compreender algo que normalmente não é atribuído a ele. A criação do gênero de emblemas populares emprega à cultura visual a mensagem principal do movimento metodista: a graça de Deus é universal e se dirige a todos os seres humanos sem distinção.

\section{Considerações finais}

Vimos que não há uma única forma de entender as gravuras encontradas nas obras de John Wesley. Há gravuras de caráter ocupacional, como printer flowers, uma função que em geral era reservada aos frontalpieces. Além disso, há um uso ornamental que se relaciona com iniciais e, parcialmente, por meio de factotums, headpieces e tailpieces. Finalmente, usase gravuras como narrativas teológico-educacionais, como é o caso das ilustrações e dos emblemas.

Em alguns casos, as próprias printer flowers contêm símbolos religiosos como um coração com chamas, um cupido, um pássaro com asas abertas, uma cabeça de anjo, um ninho de pássaros com pássaros voando, uma pessoa com cetro e espelho etc. Mas, mesmo que nesses casos o aspecto religioso seja evidente, ele se relaciona com a escolha do impressor, não do editor ou autor. A partir de 1754, os printer "flowers" se tornaram abstratos e significados simbólicos desapareceram.

23 Não excluímos a possibilidade que as picturas do primeiro e terceiro exemplo eram, pelo seu jeito de composição, originalmente printer flowers no sentido de uma reutilização das mesmas. 
Em outros casos, terceiros podem até ter colaborado na escolha ou até na discussão da concepção de uma gravura encomendada, mas, mesmo assim deve se pressupor que a decisão final era do editor ou do autor, no caso, de John Wesley. Em base dos dados unidos pensamos que a relação entre imagem e texto era vista por John Wesley de uma forma múltipla. Por sua vez, ele não rejeitou o costume das printer flowers, apesar de que os motivos não eram especificamente feitos para seus discursos. Quanto à integração de gravuras de cenas bíblicas, as ilustrações em si e em conjunto (KEMPIS, 1736) criam sua própria narrativa que não se distancia plenamente do discurso de Kempis, mas, apresentam uma ênfase própria, focando a dialética entre graça e responsabilidade. O mesmo vale para a integração de uma gravura com um crucifixo. Ao longo da sua vida teológica, Wesley revisitará esses dois temas com frequência.

Enquanto a aceitação de printer flowers na sua obra e o uso das ilustrações devem ser chamadas relativamente de convencionais, o uso nada ortodoxo de emblemas de John Wesley chama atenção. Wesley reinterpreta o gênero de emblemas por estender o grupo dos endereçados ao povo comum e por introduzir referências bíblico-teológicas para sua interpretação. Esses emblemas "ad populum" aparecem em 1748 e demonstram o contínuo esforço de John Wesley de se dirigir ao povo de uma forma criativa e contemporânea, inclusive com a ajuda da cultura visual à sua disposição.

Finalmente, podemos resumir que em conjunto se evidencia o uso da cultura visual dentro das obras. O material simbólico usado é clássico e, eventualmente, articula novas combinações de motivos ênfases metodistas. A ausência de gravuras com ilustrações maiores e composições mais complexas como na edição da Imitatio Christi nas publicações até 1736 se explica pelos custos de produção das gravuras maiores, afinal escreveu Wesley ad populum.

\section{Referências}

ANDERSON, Misty G. Imagining Methodism in Eighteenth-Century Britain: Enthusiasm, Belief \& the Borders of the Self. Baltimore: The Johns Hopkins University Press, 2012.

BAKER, Frank. "Printer's flowers as bibliographical evidence in Eighteen-Century Britain. [Texto datilografado e não publicado.]

FLEMING, Juliet. "How to look at a printed flower." In: Word \& Image, ano 22, n. 2, p. 165-187 (2006). DOI: 10.1080/02666286.2006.10435743 
FORSAITH, Peter S. Image, identity and John Wesley: a study in portraiture. Routledge, Taylor \& Francis Group, 2017.

GREEN, Ian. Print and Protestantism in Early Modern England. Oxford, Oxford University Press, 2000.

KEMPIS, Thomas à. The imitation of Christ: selections annotated \& explained. Annotation by Paul Wesley Chilcote. Adapted from John Wesley's The Christian Pattern. Woodstock, Vermont: Sky Light Illuminations, 2012.

LOFTUS, Ernest Achey. A history of the descendants of Maximilian Cole of Oxford, who flourished in the 17th century. London: Adlard \& Son, Limited, 1938.

MORGAN, David. "The image of the Protestant Bible in America." In: CHANCEY, Mark A.; MEYERS, Carol; Meyers, Eric M. (Orgs.). The Bible in the public square: it's enduring influence in American life. Atlanta, GO: SBL, 2014, p. 93-119.

MORGAN, David. The forged image: a visual history of modern Christianity. Oakland, CA: University of California Press, 2015.

RENDERS, Helmut. Um emblema social metodista: a águia e o coração com chamas, ou a misericórdia divina que permite recomeços. In: Caminhando, v. 19, n. 1, p. 83-95 (jan./ jun. 2014).

RENDERS, Helmut. "O guia medicinal Primitive Physic[k] de John Wesley de 1747: ciência, charlatanismo ou medicina social?” In: Horizonte, Belo Horizonte, v. 9, n. 21, p. 339-353 (abr./jun. 2011).

WESLEY, John (ed.). The Christian's pattern, or: a treatise of the Imitation of Christ written originally in Latin, by Thomas a Kempis; with a preface, containing an account of the usefulness of this treatise, directions for reading it with advantage, and likewise an account of this edition; compared with the original, and corrected throughout by John Wesley. London: Impresso por C. Rivington, 1736.

(ed.). The Christian's pattern, or: a treatise of the Imitation of Christ, s.l., 1735.

A short view of the difference between the Moravian Brethren, lately in England, and the reverend Mr. John Wesley and Charles Wesley. Extracted chiefly form a late Jornal. Londres: imrpesso por W. Strahan, 1745.

A short view of the difference between the Moravian Brethren, lately in England, and the reverend Mr. John Wesley and Charles Wesley. Extracted chiefly form a late Jornal. Bristol: impresso por Felix Farley, 1748.

A word in a season, or an advice to an Englishmen, 8. ed. Londres: Impresso por W. Stratham, 1745.

A word to a drunkard. [Bristol]: s.n., 1748.

A word to a freeholder. [Bristol]: Impresso [por Felix Farley], 1748.

. A word to a street-walker. [Bristol]: Impresso [por Felix Farley], 1748.

Salvation by faith, 9. ed. Londres: Impresso por H. Cock, 1750. 
Serious considerations concerning the doctrines of election and reprobation. Extracted from late author. London, 1740.

WIKINSON, Hazel. "Printers' flowers as evidence in the identification of unknown printers: Two Examples from 1715." In: The Library, ano 14, n. 1, p. 70-79, jan./mar. 2013.

\section{Páginas da internet}

S.N. “A Database of Eighteenth-Century Printers' Ornaments.” In: Fleuron. Disponível em: https://fleuronweb.wordpress.com . Acesso em: 30 set. 2018.

S.N. "Guide to the Frank Baker papers, 1641-2002 and undated, bulk 1740-1995.” In: Duke University Libraries. Disponível em: < https://library.duke.edu/rubenstein/findingaids/ bakerfrank/>. Acesso em: 30 set. 2018.

Submetido em: 8-10-2018

Aceito em: 11-4-2019 